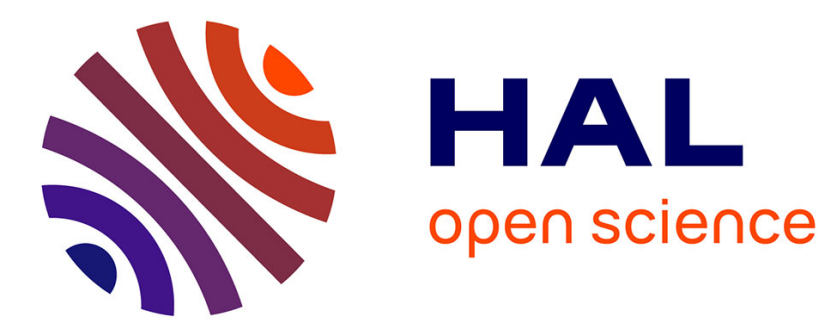

\title{
In Situ Imaging of Dislocation Expansion in FZ-Si Seeds During Temperature Ramp Heating Process
}

\author{
Maria G. Tsoutsouva, Thècle Riberi-Béridot, Gabrielle Regula, Guillaume \\ Reinhart, Jose Baruchel, Nathalie Mangelinck-Noel
}

\section{- To cite this version:}

Maria G. Tsoutsouva, Thècle Riberi-Béridot, Gabrielle Regula, Guillaume Reinhart, Jose Baruchel, et al.. In Situ Imaging of Dislocation Expansion in FZ-Si Seeds During Temperature Ramp Heating Process. physica status solidi (a), 2018, 215 (14), pp.1700758. 10.1002/pssa.201700758 . hal-01850348

\section{HAL Id: hal-01850348 \\ https://hal.science/hal-01850348}

Submitted on 27 Jul 2018

HAL is a multi-disciplinary open access archive for the deposit and dissemination of scientific research documents, whether they are published or not. The documents may come from teaching and research institutions in France or abroad, or from public or private research centers.
L'archive ouverte pluridisciplinaire HAL, est destinée au dépôt et à la diffusion de documents scientifiques de niveau recherche, publiés ou non, émanant des établissements d'enseignement et de recherche français ou étrangers, des laboratoires publics ou privés. 


\title{
In situ imaging of dislocation expansion in $\mathrm{FZ}-\mathrm{Si}$ seeds during
}

\section{temperature ramp heating process}

\author{
Maria G. Tsoutsouva ${ }^{()^{* *}}$, Thècle Riberi-Béridot ${ }^{(a)}$, Gabrielle Regula ${ }^{(a)}$, Guillaume Reinhart $^{(a)}$, \\ José Baruchel ${ }^{(b)}$, Nathalie Mangelinck-Noël ${ }^{(a)^{*}}$ \\ (a) Aix-Marseille Université, CNRS, IM2NP UMR CNRS 7334, Campus Saint Jérôme, case \\ 142, 13397 Marseille Cedex 20, France. \\ (b)ESRF, 71, avenue des Martyrs, CS40220, 38043 Grenoble Cedex 9, France.
}

\begin{abstract}
*Corresponding author: Dr. N. Mangelinck-Noël, Aix-Marseille Université, CNRS, IM2NP UMR CNRS 7334, Campus Saint Jérôme, case 142, 13397 Marseille Cedex 20, France, + 33 (0) 491288737

e-mail: nathalie.mangelinck@im2np.fr
\end{abstract}

**Current affiliation: Depart. of Physics, Norwegian University of Science and Technology (NTNU), 7491, Trondheim, Norway e-mail: maria.tsoutsouva@ntnu.no

\begin{abstract}
The impact of the thermal field in a directional solidification furnace on the generation and propagation of dislocations is investigated in intrinsic floating zone single crystal silicon. Seeds with different crystallographic orientations are wire-cut from mono-crystalline wafers and dislocation sources are solely left at the edges. Thermal annealing experiments are carried out in situ at the European synchrotron radiation facility and the evolution of the silicon crystalline quality is studied by X-ray diffraction imaging technique. At $1073 \mathrm{~K}$, dislocations nucleate only at the edges and their strain field remains local. At higher temperature (1373 K), dislocations propagate throughout the entire width of the seed via the preferential activation of slip planes, related to the crystallographic orientation of the seed. These results confirm the high importance of seed preparation in mono - like silicon growth process. Both mechanical
\end{abstract}


and chemical polishing of all seed surfaces, including their edges, are mandatory to prevent dislocation expansion and multiplication.

Keywords: X-ray Bragg diffraction imaging, dislocations, thermal annealing, FZ Si, directional solidification

\section{Introduction}

Mono - like silicon (ML - Si) growth is an attractive technique because it merges the high quality monocrystalline and the low cost multi - crystalline manufacturing processes in a single, improved hybrid version that gives square - shaped ingots at high productivity levels. In addition, $\mathrm{ML}-\mathrm{Si}$ has been found to be less sensitive to light-induced degradation than $\mathrm{Cz}-$ $\mathrm{Si}^{[1]}$ In this technique, the Si grows by directional solidification from a pavement of mono crystalline seeds placed on the bottom of the crucible. Despite that the wafers obtained from these ingots have been shown to result in high efficiency solar cells, ${ }^{[1-3]}$ several challenges have emerged and prevented the wide spread adoption of ML - Si mass production. Among these are the formations of dislocations initiated at the bottom of the ingot either in the seeds and/or at their junctions, leading to the formation of electrically active small angle grain boundaries. These small angle grain boundaries multiply and propagate during the growth process along the height of the solidified ingot degrading the photovoltaic performance of the obtained wafers. The generation of dislocations in ML-Si has previously been related to the relative misorientation and the gap between the seeds ${ }^{[4-7]}$ as well as the presence of precipitates. ${ }^{[8,9]}$ Furthermore, the formation of dislocations in the preserved seeds that propagate in the upgrown crystal during the solidification process has also been investigated. ${ }^{[10]}$ Their generation has been attributed to different mechanisms: i) thermal stresses induced during heating and cooling down process, ${ }^{[11]}$ ii) poor surface preparation of the seeds, ${ }^{[12]}$ iii) weight and/or indentation by the silicon feedstock, ${ }^{[7,13]}$ iv) contact points at the interface between adjacent 
seeds, $\left.{ }^{[12]} \mathrm{v}\right)$ indentation by contact points between the seeds and the $\mathrm{Si}_{3} \mathrm{~N}_{4}$ coating/crucible interface at the bottom of the crucible, ${ }^{[7,12]} \mathrm{vi}$ ) formation of precipitates (silicides) punching out dislocations, such as $\mathrm{SiO}_{2}$ precipitates formed at high temperature during long annealing. ${ }^{[14]}$ V.A Oliveira ${ }^{[10]}$ investigated the role of $\mathrm{SiO}_{2}$ precipitates on the dislocation formation in the seeds of mono - like ingots in FZ (low oxygen content) seed instead of a $\mathrm{Cz}$ for the crystallization. The characterization of the seed zone by $\mathrm{X}$ - ray Bragg diffraction imaging showed that the dislocation density and the cellular dislocation network in the FZ Si seed was quite similar to the one present in the $\mathrm{CZ} \mathrm{Si}$ seed. This observation proves that $\mathrm{SiO}_{2}$ precipitates have none or very small contribution in the dislocation density inside the seeds of ML - Si ingots. Nevertheless, the principal sources and the mechanism of dislocation formation and propagation in the seed of $\mathrm{ML}$ - Si remain unclear. Assumptions have been made after ex situ characterization of the grown ingot but this approach is not able to isolate the dislocation sources and examine the internal spatial deformation distribution to provide an in-depth understanding. Moreover, additional stresses induced in the system during cooling down very likely generate new dislocations and modify those that have already been formed during heating up and solidification making the understanding from the ex situ investigations even more challenging. It becomes clear though that the current research progress is limited by the difficulty of accessing, understanding and controlling the physicochemical mechanisms acting during the heating - melting - solidification process.

This work focuses on the protocol of the heating process of $\mathrm{FZ}-\mathrm{Si}$ seeds having different crystallographic orientation but a common direction normal to their surface and its impact on the dislocation formation. For this purpose, heating ramp test, at high temperature (up to 1623 $\mathrm{K})$, is performed using $\mathrm{FZ}-\mathrm{Si}$ seeds in a directional solidification furnace. The uniqueness of our approach is that the dislocation formation in the Si seeds, as a function of the temperature increase, is followed in real time by synchrotron $\mathrm{X}$ - ray Bragg diffraction imaging techniques. 
This experiment allows us not only to identify the sources of dislocation generation and follow

their evolution during heating but also to determine the activated slip planes with regards to the seed crystallographic orientation. An analysis on the role of seed surface preparation (front, back and edges), the seed holding system, the temperature levels, the temperature gradients (unavoidable or mastered) and crystallographic orientation on the morphology of the formed dislocations is performed.

\section{Experimental Procedure}

Heating ramp experiments are carried out in situ inside GaTSBI (Growth at high Temperature observed by Synchrotron Beam Imaging) device at beam line BM05 at the European Synchrotron Radiation Facility (ESRF). GaTSBI is a specially designed experimental installation composed of a high temperature directional solidification (DS) furnace employed in conjunction with synchrotron radiation X-ray imaging techniques. So far, GaTSBI has been used to perform in situ solidification experiments of mono - crystalline and multi - crystalline silicon to investigate the growth phenomena that occur during the solidification process. A detailed description of the whole equipment and the previously obtained results can be found in references. ${ }^{[15-19]}$

In the present work, we take advantage of this unique experimental set - up to follow in real time the generation and propagation of dislocations by $\mathrm{X}$ - ray Bragg diffraction imaging, during heating ramp experiments of $\mathrm{FZ}-\mathrm{Si}$ seeds having different in plane crystallographic orientations. A schematic representation of the diffraction imaging principle can be seen in figure 1a. The DS furnace is based on two resistive heating elements (top and bottom) schematically depicted in figure 1a and is operated under a secondary dynamical vacuum $\left(\sim 10^{-}\right.$ ${ }^{6}$ mbar). X-ray Bragg diffracted images, corresponding to different $\{h k l\}$ diffracting planes, are regularly recorded on $\mathrm{X}$ - ray sensitive films (AGFA Structurix D3-SC, $17.6 \times 12.5 \mathrm{~cm}^{2}$ ) 
positioned at a distance of $300 \mathrm{~mm}$ from the seed. Due to the small beam divergence and to its large size, the whole width of the seed is illuminated and the recorded Bragg diffraction images contain information on the level of crystal perfection and/or deformation.

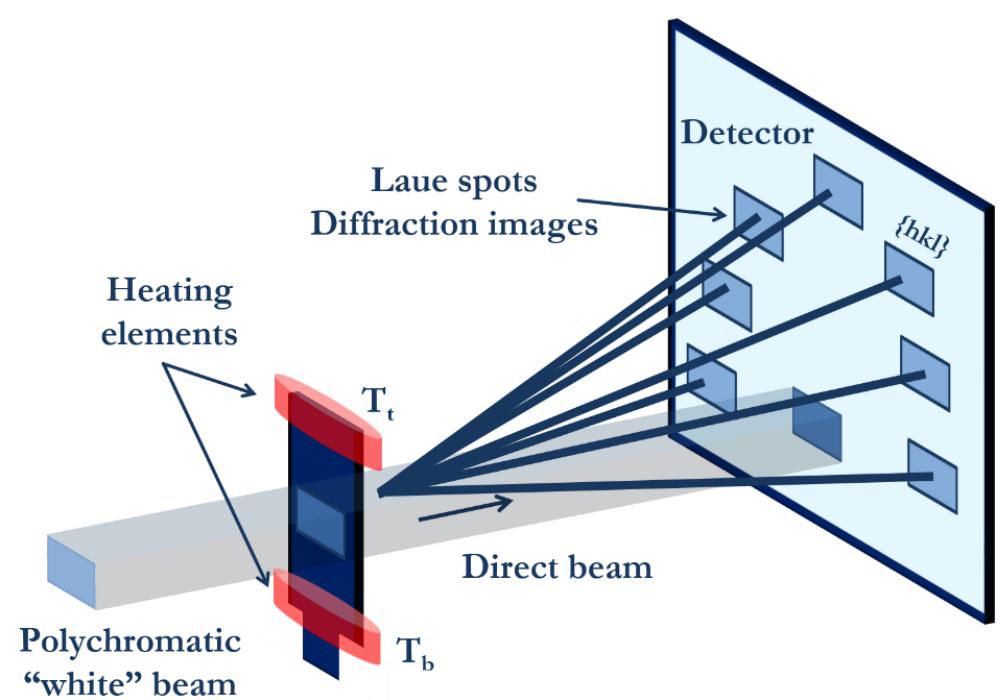

(a)

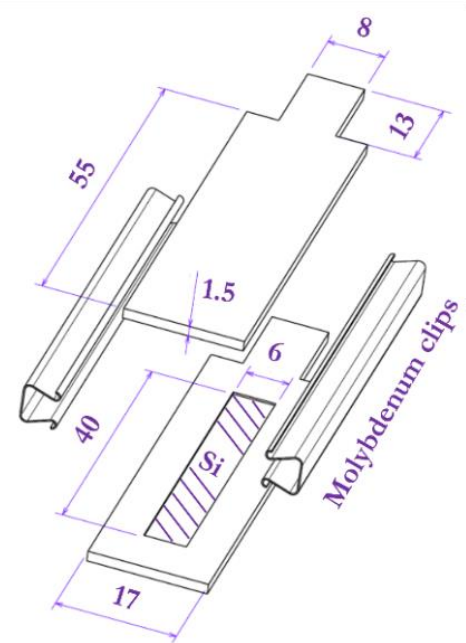

(b)

Figure 1: Sketches of a) the $X$-ray diffraction imaging configuration, where $T_{b}$ and $T_{t}$ are the bottom and top heater temperatures respectively and b) the pyrolytic $\mathrm{BN}$ crucible where the Si seed is housed: the purple hatched rectangle highlights the Si seed which is inserted in an adapted hollow having a $(300 \pm 30) \mu \mathrm{m}$ depth. Dimensions are given in $\mathrm{mm}$. The Mo clips are used to maintain both parts of the $\mathrm{BN}$ crucible, holding them tight together. 
Bragg diffraction imaging consists in studying the fine structure of a Bragg spot, which contains information about the deviation from the perfect crystal structure. This is a powerful technique dedicated to the visualization of defects-induced strain in general and in particular, of dislocations, inclusions, strong impurity gradients present in the mono - crystal volume. Indeed, it is sensitive to long range distortion fields and / or strain fields associated with a crystal deformation. This is made possible, because these distortion fields affect the diffracted intensity, so that a contrast (non - homogeneous intensity distribution) is created in the recorded image.

Seeds are appropriately cut with a diamond wire (having particles of $60 \mu \mathrm{m}$ in size) saw from a double-sided mechano - chemically polished intrinsic (resistivity beyond $5000 \Omega \mathrm{cm}$ ) FZ wafer $50.8 \mathrm{~mm},\{110\}$ in surface orientation provided by SIL'TRONIX Silicon Technologies. No further chemical polishing has been applied afterwards, leaving the edge damage due to sawing.

The FZ - Si seeds are housed inside a pyrolytic BN crucible (Figure 1b) one side of which has a hollow with the following dimensions: length $40 \mathrm{~mm}$, width $6 \mathrm{~mm}$ and depth 0.35 $\mathrm{mm}$. The pyrolytic $\mathrm{BN}$ has been chosen as the material for the crucible, since it is almost transparent to X-rays, in the range of the used wavelengths, does not give additional diffraction images to the detector, presents stability at high temperatures and can be machined. To limit any stresses that can be introduced in the seed during heating, even though the low difference in thermal expansion coefficient between $\mathrm{Si}$ and $\mathrm{BN}$, the seed dimensions have been defined to be $(38.0 \pm 0.6) \mathrm{mm} \times(5.8 \pm 0.6) \mathrm{mm} \times(0.30 \pm 0.01) \mathrm{mm}$ that are shorter dimensions in length and width as compared to the hollow of the BN crucible. However, the thickness of the seed and the depth of the hollow in the BN are nearly alike, since usually, the seed is partially melted and Si flow along the BN walls should be avoided for further studies of recrystallization from 
the seed. Noteworthy, the Mo clips allow both part of the crucible being tightly maintained in

\section{designed to impose a dominant vertical temperature gradient that allows vertical directional}

\section{solidification while smaller amplitude radial and transverse gradients might exist.}

The heating ramp process is the same for all the examined cases and is presented, in figure $\mathbf{2}$, for the representative case of the seed oriented $<100\rangle$ along the vertical direction (length direction), $\mathrm{FZ}_{<100>}$. The seed is heated by applying the same temperature at the bottom and top resistance of the furnace during 2 hours and 40 minutes, up to $1373 \mathrm{~K}$ and then a temperature gradient of $30 \mathrm{~K} / \mathrm{cm}$ is imposed during 30 minutes of heating.

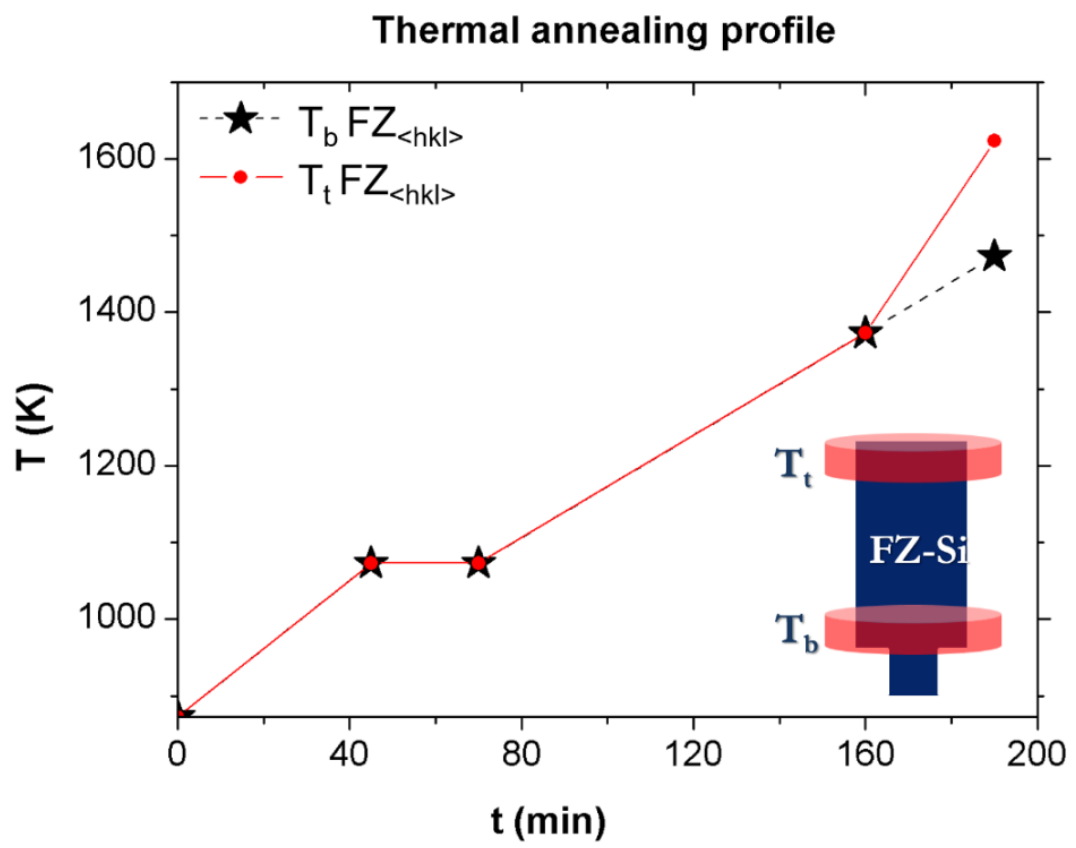

Figure 2: Thermal annealing profile, where $T_{b}$ and $T_{t}$ are the applied-temperatures respectively on the bottom and the top heaters. 


\section{Experimental results}

To study the impact of both mechanical and thermomechanical stresses on the generation, multiplication, propagation and interaction of dislocations in $\mathrm{FZ}-\mathrm{Si}$ seeds, multiple Bragg diffraction images are recorded during the high temperature ramp heating process. Figure 3 shows selected diffraction images recorded during heating for the three $\{110\}$ seeds voluntarily cut with different crystallographic orientations along the vertical direction corresponding as well to the applied temperature gradient direction.

In all cases, even at low temperature $(873 \mathrm{~K})$, both side edges of the seed are darker in comparison to the central part of the crystal, similarly to figures $\mathbf{3 a}, \mathbf{3 d}$ and $\mathbf{3 g}$. As the temperature increases, the Bragg diffraction images reveal the propagation of dislocations, initiated at the edges, throughout the whole width and length of the seed. These dislocations, which appear as dark parallel straight lines in the images, follow specific crystallographic directions (Peierls valleys, <110>) that are different in each seed and are related to its crystallographic orientation. It is worth noting that this kind of dislocations appear in $\mathrm{FZ}_{<100>}$ at 1373K (horizontal dark lines in figure 3b), whereas no temperature vertical gradient is applied. 

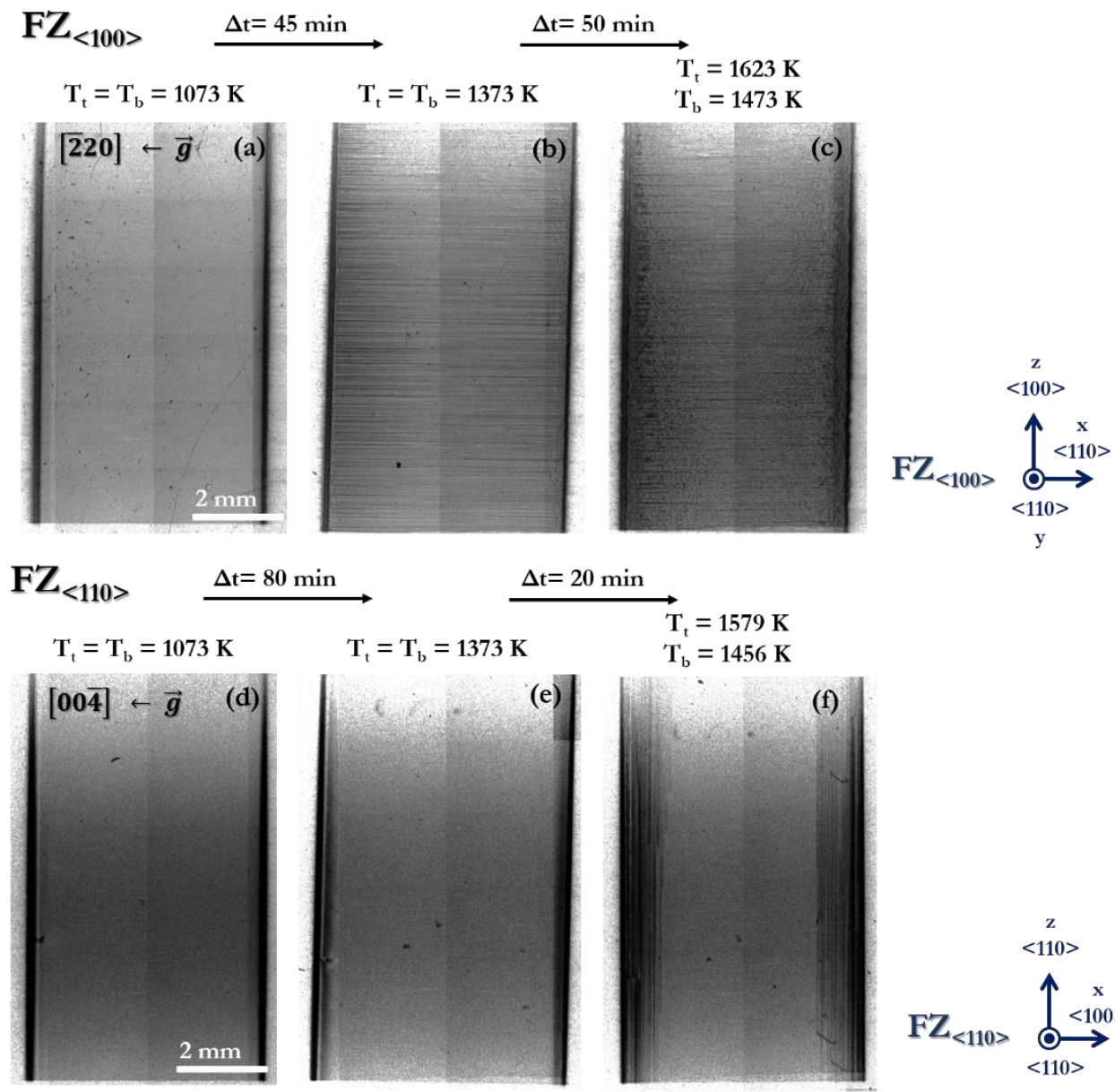

(f)
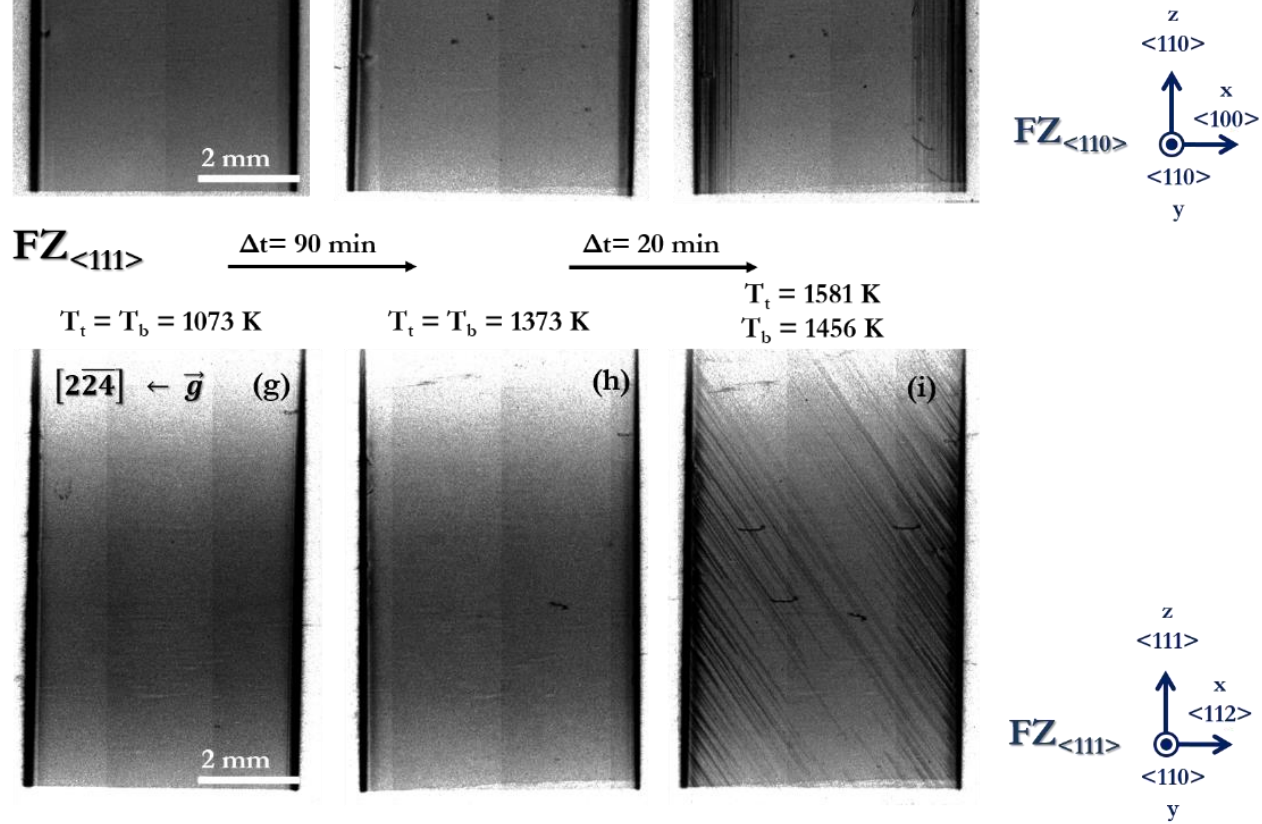

Figure 3: Bragg diffraction images of the $\mathrm{FZ}-\mathrm{Si}$ seeds during heating ramp. $\vec{g}$ is the diffraction vector projected on the plane of the figure. Each horizontal series of three pictures corresponds to the same seed $\mathrm{FZ}<\mathrm{hkl}>$ having the vertical length orientation $\langle\mathrm{hkl}\rangle$ and the same diffraction vector $\vec{g} ;(a-b),(d-e),(g-h)$ : no vertical applied temperature gradient; (c), (f), and (i), a $30 \mathrm{~K} / \mathrm{cm}$ vertical gradient $G_{l}$ is applied. 
In the examined seeds, we observe three different morphologies of dislocations that are

gathered and presented in magnified images in figure 4. Figures $\mathbf{4 a}, \mathbf{b}, \mathbf{c}$ show the morphology A of dislocations that appear as straight long segments in seeds $\mathrm{FZ}_{<100>}, \mathrm{FZ}_{<110>}$ and $\mathrm{FZ}_{<111>}$ respectively. In addition to this morphology of dislocations, there are also many short-tangled dislocation (morphology B) elongated up to $300 \mu \mathrm{m}$ from the edges of the specimen (Figure 4d). Moreover, some straight and short scarce "staple-like" shaped dislocation segments (morphology $\mathrm{C}$ in figures $4 \mathbf{e}$ and $\mathbf{f}$, triangles in orange in figures $\mathbf{3 f}$ and $3 \mathbf{i}$ ) are also present. The latter seems to interact with morphology A dislocations (see figures $4 \mathbf{e}$ and f).

Morphology

A

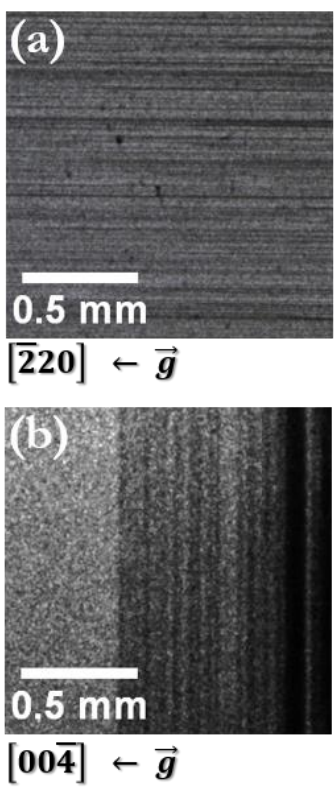

Morphology

B

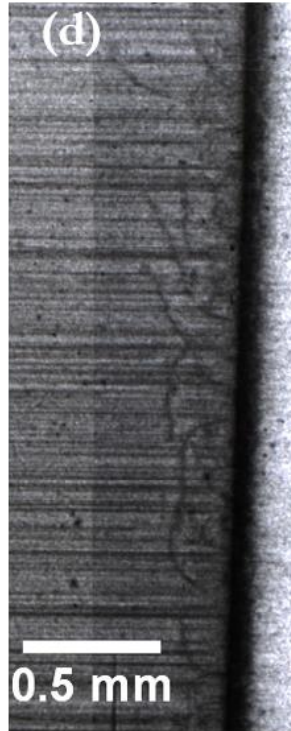

$[\overline{2} 20] \leftarrow \vec{g}$
Morphology

C

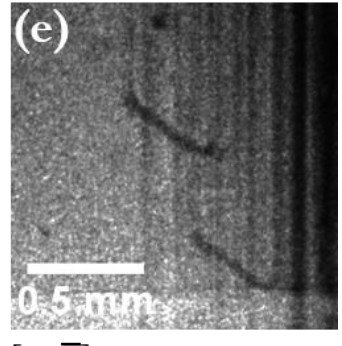

$[00 \overline{4}] \leftarrow \vec{g}$

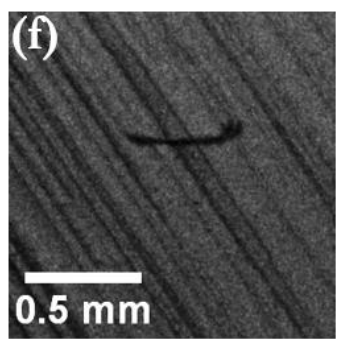

$[\mathbf{2 4}] \leftarrow \vec{g}$

Figure 4: Magnified Bragg diffraction images of the three different morphologies of dislocations observed in $\mathrm{FZ}$ - Si seeds during heating ramp. $\vec{g}$ is the diffraction vector projected on the plane of the figure. (a and d) correspond to the seed $F Z_{<100>}$ (figure $3 \mathrm{~b}$ ), (b and e) correspond to the seed $F Z_{<110>}$ (figure $3 f$ ) and (c and f) correspond to the seed $F Z_{<111>}($ figure 3i). 
The dislocation density in the three examined specimens is not uniform and varies in different areas in the same seed. However, indicative values of the dislocation density can be given according to the contrast of the Bragg diffraction images. In diffraction images, a single dislocation induces a contrast so that in the uniformly grey zones that are free of dark segments or lines, the dislocation density is $0 \mathrm{~cm}^{-2}$. In areas that appear very dark in the diffraction images, such as the edges of the seeds, the dislocation density is $\geq 10^{6} \mathrm{~cm}^{-2}$, in areas where individual lines can be distinguished, it is estimated to $\sim 10^{4} \mathrm{~cm}^{-2} .{ }^{[20]}$

To evidence the possible $\{111\}$ slip planes to be activated with regards to the crystallographic orientations of each seed, figure 5 presents their stereographic projections: blue dots show the crystallographic poles of the $\{111\}$ slip planes which are not activated, red dots the $\{111\}$ which are experimentally activated, and orange triangles indicate those in which dislocation morphologies $\mathrm{C}$ are likely lying, respectively. Indeed, the main prints of the activated $\{111\}$ at the seed surface for morphology A, are horizontal, vertical and diagonal for

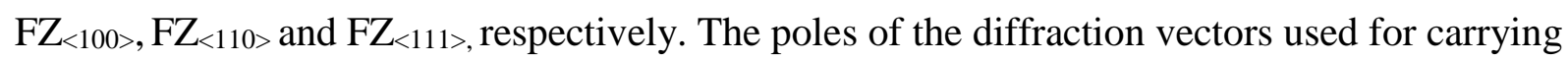
out Bragg diffraction images, presented in figures 3 and 4, are marked in green in figure 5. Due to the cubic diamond factor structure, such as silicon, (110), (100) and (112) cannot diffract: thus, in the present diffraction experiments, $[\overline{2} 20]$ parallel to $[\overline{1} 10],[00 \overline{4}]$ parallel to $[00 \overline{1}]$ and $[2 \overline{24}]$ parallel to $[1 \overline{12}]$ are the diffraction vectors. 


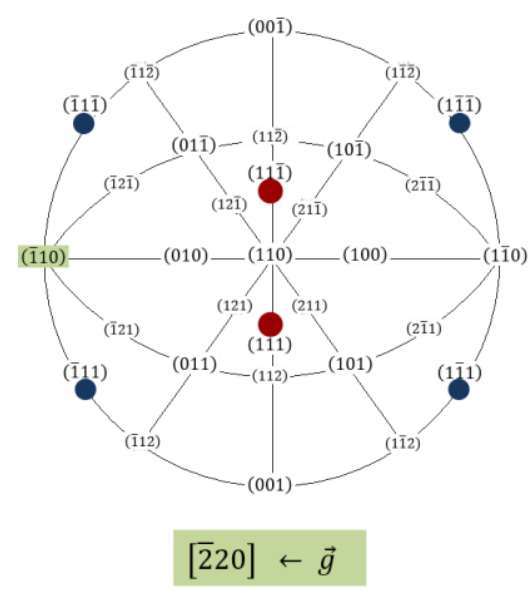

(a)

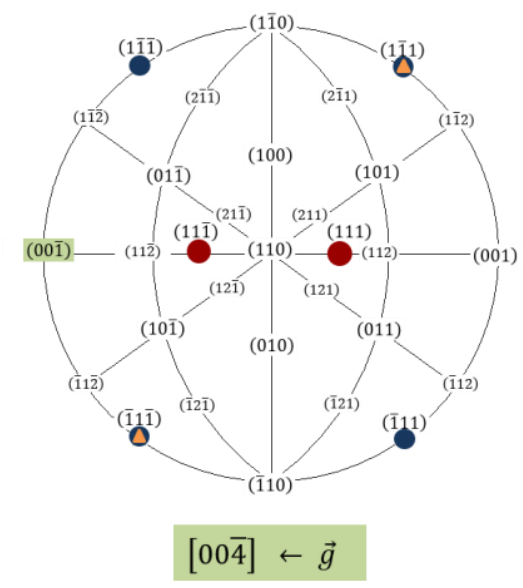

(b)

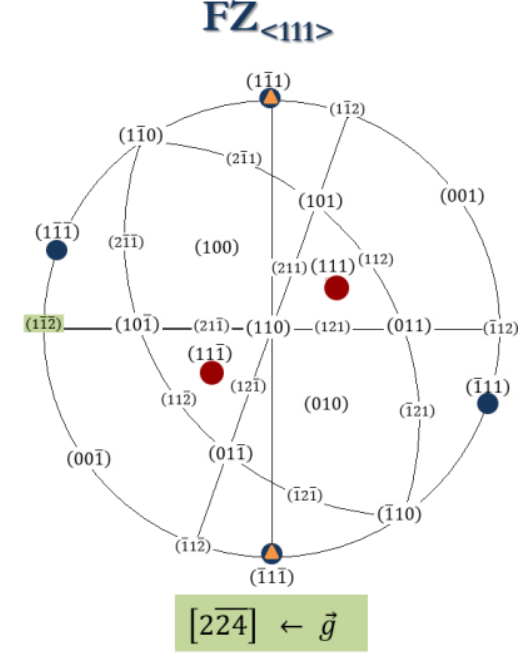

(c)

Figure 5: Stereographic projections of the studied $\mathrm{FZ}_{<\mathrm{hkl}}>-\mathrm{Si}$ seeds. $\langle$ hkl $>$ is the direction along the length of the rectangular seeds. Red dots indicate the crystallographic poles of the primary activated $\{111\}$ slip planes (morphology A). Orange triangles correspond to possible additional activated $\{111\}$ (morphology $C$ ). In green are marked the corresponding poles of the diffraction vectors of images, presented in figures 3 and 4.

The fact that some gliding systems are activated or not, and some dislocation sets are present or not in the seeds is discussed in part 4. An analysis of the dislocation sources, the role of temperature and of the crystallographic orientation on the generation and propagation mechanisms of dislocations is performed. This analysis focuses on morphology A dislocations that are the most abundant and that propagate all along the width or length of the seeds.

\section{Discussion}

$\mathrm{FZ}-\mathrm{Si}$ is the closest possible to a perfect crystal, with very low impurity concentration and no as grown extended defects, as confirmed in figures 3a, d, g. The dark edges of the seeds, in these Laue spots, prove that these zones are more strained than the internal part of the $\mathrm{Si}$ crystal denoting that the wire sawing process introduces local stacked strain in these regions, 
due to the mechanical interaction of the abrasive grit with the Si. The uniform gray contrast "perfect" from the crystalline point of view and regarding strain. Thus, the sole possible source of dislocations found in the seeds is the surface damage induced by the sawing step. Saw damage is well documented as being present in the first few micrometers of an as-cut wafer, ${ }^{[21]}$ the work hardening depending of course on the diameter of the diamond particles present on the wire. Saw damage induces residual stresses, compressive in nature in the range from -20 $\mathrm{MPa}$ to $-85 \mathrm{MPa}$ including stresses having a component in both the $\mathrm{x}$ - and $\mathrm{y}$ - coordinate directions, namely, $\sigma_{\mathrm{xx}}$ and $\sigma_{\mathrm{yy}}{ }^{[22]}$ When those stresses exceed the Si critical shear stress, they cause plastic deformation and/or micro cleavage. ${ }^{[23]}$ However, the presence of this local strain remaining after the sawing step can only explain the formation of the morphology B dislocations. It cannot be the origin of the driving force for the propagation of morphology A dislocations while heating, through the crystal width or length, via the activation of different specific slip planes in each case. An external stress beyond the critical shear stress for the activation of the specific slip planes at the corresponding temperature should be applied to the system to explain the propagation length of morphology A dislocations. Let us have a look at the effect of three stress directions, regardless their origin but perpendicular to each seed surfaces ((xy) plane, bottom; (xz) plane, thickness; (yz) plane, front and back surfaces of the seed). This uniaxial stress and thus the Schmid's factor $m$ of the corresponding inducedresolved shear stresses for the three orientations of the seeds can be calculated for each slip system. An example of the Schmid factor calculation in a cubic crystal for a stress applied parallel to [110], on the slip plane (111), for a slip direction (Burgers vector) $[01 \overline{1}]^{[24]}$ is given by the following equation: 


$$
\begin{gathered}
\boldsymbol{m}_{[\mathbf{0 1}](111)}=\frac{(\mathbf{1} *(-\mathbf{1})+\mathbf{1} * \mathbf{1}+\mathbf{1} * \mathbf{0})}{\sqrt{\left(\mathbf{1}^{2}+\mathbf{1}^{2}+\mathbf{1}^{2}\right)} * \sqrt{\left((-1)^{2}+\mathbf{1}^{2}+\mathbf{0}^{2}\right)}} * \frac{(\mathbf{0} *(-1)+1 * 1+(-1) * 0)}{\sqrt{\left(\mathbf{0}^{2}+\mathbf{1}^{2}+(-1)^{2}\right)} * \sqrt{\left((-1)^{2}+\mathbf{1}^{2}+\mathbf{0}^{2}\right)}}= \\
\frac{0}{\sqrt{3} * \sqrt{2}} * \frac{1}{\sqrt{2} * \sqrt{2}}=0
\end{gathered}
$$

The values of $m$ for each glide system and each stress direction allows discriminating which glide planes can be activated (if $m \neq 0$ ) or not (if $m=0$ ) and which ones are the most probable to release the applied stress, that are the glide systems having the highest $\mathrm{m}$ value called primary glide systems. The secondary glide systems can still be activated if their resolved shear stress remains beyond the critical threshold to move dislocations at the studied temperature. The corresponding results are given in table $\mathbf{1 .}$

Table 1: Schmid's factors $\mathrm{m}$ calculated for all $\mathrm{FZ}<\mathrm{hkl}>$ seeds considering the presence of a uniaxial stress applied along the three perpendicular dimensions of the seeds (width $\sigma_{\mathrm{w}}$, length $\sigma_{\mathrm{l}}$, thickness $\sigma_{t}$ ). The column highlighted in red, points out the directions of the seed along which the applied stress corresponds to the experimental observations of

\begin{tabular}{|c|c|c|c|c|}
\hline \multicolumn{5}{|c|}{$F Z_{<100>}$} \\
\hline \multicolumn{2}{|c|}{ Uniaxial stress } & $\sigma_{w}$ & $\sigma_{l}$ & $\sigma_{t}$ \\
\hline \multicolumn{2}{|c|}{ Applied stress direction } & {$[\overline{\mathbf{1 1}} \mathbf{1 0}]$} & {$[\mathbf{0 0 \overline { 1 }}]$} & [110] \\
\hline Slip plane & Burgers vector & \multicolumn{3}{|c|}{ Schmid's factors } \\
\hline (111) & {$[\overline{\mathbf{1} 10}]$} & $\mathbf{0}$ & $\mathbf{0}$ & $\mathbf{0}$ \\
\hline (111) & {$[\mathbf{0 1 \overline { 1 }}]$} & $\mathbf{0}$ & -0.408 & 0.408 \\
\hline (111) & {$[\mathbf{1 0 \overline { 1 }}]$} & $\mathbf{0}$ & -0.408 & 0.408 \\
\hline$(\mathbf{1 1} \overline{1})$ & {$[\overline{\mathbf{1} 10}]$} & $\mathbf{0}$ & $\mathbf{0}$ & $\mathbf{0}$ \\
\hline$(\mathbf{1 1} \overline{1})$ & [011] & $\mathbf{0}$ & -0.408 & 0.408 \\
\hline$(11 \overline{1})$ & {$[101]$} & $\mathbf{0}$ & -0.408 & 0.408 \\
\hline$(\overline{\mathbf{1}} 11)$ & {$[\mathbf{0 1 \overline { 1 }}]$} & 0.408 & -0.408 & $\mathbf{0}$ \\
\hline$(\overline{\mathbf{1} 11})$ & {$[110]$} & $\mathbf{0}$ & $\mathbf{0}$ & $\mathbf{0}$ \\
\hline$(\overline{\mathbf{1} 11})$ & {$[101]$} & -0.408 & 0.408 & $\mathbf{0}$ \\
\hline$(\overline{\mathbf{1}} \mathbf{1} \overline{\mathbf{1}})$ & [011] & 0.408 & -0.408 & $\mathbf{0}$ \\
\hline$(\overline{\mathbf{1} 1 \overline{\mathbf{1}}})$ & {$[110]$} & $\mathbf{0}$ & $\mathbf{0}$ & $\mathbf{0}$ \\
\hline$(\overline{\mathbf{1}} \mathbf{1} \overline{\mathbf{1}})$ & {$[\mathbf{1 0} \overline{\mathbf{1}}]$} & -0.408 & 0.408 & $\mathbf{0}$ \\
\hline
\end{tabular}
morphology A dislocation propagation. 


\begin{tabular}{|c|c|c|c|c|}
\hline \multicolumn{5}{|c|}{$F Z_{<110>}$} \\
\hline \multicolumn{2}{|c|}{ Uniaxial stress } & $\sigma_{w}$ & $\sigma_{1}$ & $\sigma_{t}$ \\
\hline \multicolumn{2}{|c|}{ Applied stress direction } & {$[00 \overline{1}]$} & {$[\mathbf{1 1} 0]$} & {$[110]$} \\
\hline Slip plane & Burgers vector & \multicolumn{3}{|c|}{ Schmid's factors } \\
\hline (111) & {$[\mathbf{0 1 \overline { 1 }}]$} & -0.408 & $\mathbf{0}$ & 0.408 \\
\hline (111) & {$[\mathbf{1} \overline{\mathbf{1}} \mathbf{0}]$} & $\mathbf{0}$ & $\mathbf{0}$ & $\mathbf{0}$ \\
\hline (111) & {$[\mathbf{1 0} \overline{1}]$} & 0.408 & $\mathbf{0}$ & 0.408 \\
\hline (1)11) & {$[01 \overline{1}]$} & -0.408 & -0.408 & $\mathbf{0}$ \\
\hline (1) $1 \overline{1})$ & {$[110]$} & $\mathbf{0}$ & $\mathbf{0}$ & $\mathbf{0}$ \\
\hline (1̄i1) & {$[011]$} & 0.408 & -0.408 & $\mathbf{0}$ \\
\hline$(\mathbf{1 1} \overline{\mathbf{1}})$ & {$[\mathbf{1 1} \overline{1} 0]$} & $\mathbf{0}$ & $\mathbf{0}$ & $\mathbf{0}$ \\
\hline$(\mathbf{1 1} \overline{\mathbf{1}})$ & [101] & -0.408 & $\mathbf{0}$ & 0.408 \\
\hline$(\mathbf{1 1} \overline{\mathbf{1}})$ & {$[011]$} & -0.408 & $\mathbf{0}$ & 0.408 \\
\hline$(\overline{\mathbf{1 1 1}})$ & {$[\mathbf{1 1 0}]$} & $\mathbf{0}$ & $\mathbf{0}$ & $\mathbf{0}$ \\
\hline$(\mathbf{1 1 1})$ & {$[\mathbf{1 0 1}]$} & -0.408 & 0.408 & $\mathbf{0}$ \\
\hline$(\mathbf{1 1 1})$ & {$[\mathbf{1 0 \overline { 1 }}]$} & 0.408 & 0.408 & $\mathbf{0}$ \\
\hline \multicolumn{5}{|c|}{$F Z_{\langle 111\rangle}$} \\
\hline \multicolumn{2}{|c|}{ Uniaxial stress } & $\sigma_{w}$ & $\sigma_{1}$ & $\sigma_{t}$ \\
\hline \multicolumn{2}{|c|}{ Applied stress direction } & {$[\mathbf{1 1 \overline { 1 }}]$} & {$[\mathbf{1 1} 1]$} & [110] \\
\hline
\end{tabular}

\begin{tabular}{|c|c|c|c|c|}
\hline Slip plane & Burgers vector & \multicolumn{3}{|c|}{ Schmid's factors } \\
\hline (111) & {$[\mathbf{1 1} \overline{1} 0]$} & -0.272 & 0.272 & $\mathbf{0}$ \\
\hline (111) & {$[\mathbf{1 0 \overline { 1 }}]$} & -0.408 & $\mathbf{0}$ & 0.408 \\
\hline (111) & {$[01 \overline{1}]$} & -0.136 & -0.272 & 0.408 \\
\hline (111) & {$[\mathbf{1} \overline{10}]$} & 0.272 & -0.272 & $\mathbf{0}$ \\
\hline$(\mathbf{1 1 1})$ & {$[101]$} & -0.136 & -0.272 & 0.408 \\
\hline$(\mathbf{1 1 1})$ & {$[011]$} & -0.408 & $\mathbf{0}$ & 0.408 \\
\hline (1) 11$)$ & {$[\mathbf{1 0 \overline { 1 }}]$} & $\mathbf{0}$ & $\mathbf{0}$ & $\mathbf{0}$ \\
\hline (1) $\overline{11})$ & {$[110]$} & $\mathbf{0}$ & $\mathbf{0}$ & $\mathbf{0}$ \\
\hline (1) 11$)$ & [011] & $\mathbf{0}$ & $\mathbf{0}$ & $\mathbf{0}$ \\
\hline$(\overline{111})$ & {$[01 \overline{1}]$} & 0.272 & -0.272 & $\mathbf{0}$ \\
\hline$(\overline{111})$ & {$[110]$} & $\mathbf{0}$ & $\mathbf{0}$ & $\mathbf{0}$ \\
\hline$(\overline{111})$ & {$[101]$} & -0.272 & 0.272 & $\mathbf{0}$ \\
\hline
\end{tabular}

Table 1 underlines that in $\mathrm{FZ}_{<100>}$ for example, if a uniaxial stress along [110] were responsible

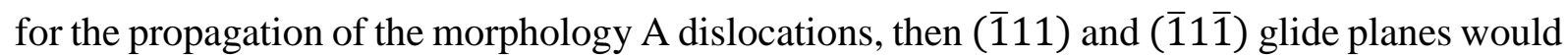
have been activated. Hence, in that case, a diagonal dislocation pattern would have been observed according to the stereographic projection (see figure 5a). However, since the dislocation pattern is horizontal, the activated planes can only be (111) or (11) $)$. If the uniaxial stress along [001] would have expand morphology A dislocations, all the slip planes would have been activated, which is not the case. The same reasoning holds for the two other seed 
orientations. Consequently, it is eventually found that the activation of the respective slip planes

for the three seeds (Figures $\mathbf{5} \mathbf{a}, \mathbf{b}, \mathbf{c}$ ) can only be caused by an applied external force perpendicular to the largest surface of the seeds, inducing a stress along $<110\rangle$.

Wittge et al. ${ }^{[25,26]}$ investigated the dislocation sources and slip band nucleation from indents on silicon wafers and they also observed an asymmetry on the slip plane activation that was attributed to the different temperature gradient within their furnace in the vertical and horizontal directions. They also found slip nucleation at the periphery of the wafer which cannot be correlated with the intended points and they did not determine the edge defects that induced such a slip nucleation.

On the one hand, due to the complexity of the set up system in the furnace (BN crucible, Mo tweezers, graphite fixing screw, etc...), it is not possible to simulate the exact thermal gradients that may exist in the sample. On the other hand, the impact of the thermo-mechanical stresses induced in the sample by the heating ramp and/or the applied temperature gradients would require analyzing a three-dimensional, non-linear, multi-body contact and stress simulation, which is out of the scope of this manuscript. However, a simple stress tensor matrix calculation is used to determine the possible activated glide systems (see in the appendix the extended calculations for $\left.\mathrm{FZ}_{<100>}\right)$. It shows that the possible temperature gradients that may exist in the furnace should activate all the glide planes in our samples, which is not observed. Thus, it is likely that the driving force expanding the dislocations in the seed is related to mechanical stresses induced by the complex crucible / sample holder system.

The present experimental results show that the state of the side surfaces of the seed after wafering process can be the origin of dislocation nuclei. The dislocation velocity depends on the shear stress applied on the different slip planes and on the temperature if we consider thermally activated dislocation glide. Therefore, dislocation nucleation and propagation could 
be reduced by optimizing the seed surface preparation in order to eliminate the dislocation crucible in such a way that the resolved shear stress applied on the slip glide systems becomes lower than the critical resolved shear stress to develop dislocations.

To further investigate the impact of the saw process on the generation of dislocations during the heating process, an experiment is performed, under the same experimental conditions, using a seed that has been chemically polished, prior HF bath followed by a CP4 polishing with a newly fabricated solution at room temperature during $3 \mathrm{~min}$ after the cutting process, in order to smoothen the damaged zone at the edges. Using this process, we attempt to remove all dislocation sources induced by sawing and prevent the dislocation propagation during the temperature ramp. However, the sole chemical polishing is not efficient enough: a fine combination of mechanical and chemical polishing is mandatory. The obtained results (not presented in the present manuscript) as well as the conclusions withdrawn, concerning the relationship between the seed orientation and the preferential activation of slip planes, are identical with those presented in this work. The only remarkable difference is that the dislocation propagation event has been delayed during the heating process with prior chemical polishing. Instead of a dislocation propagation occurrence at $1423 \mathrm{~K}$, this event happens at 1673 $\mathrm{K}$ just before the melting started. This fact denotes that the dislocation sources induced during the sawing process have been attenuated by chemical polishing but they have not been fully removed. Nonetheless, it should also be noticed that both front and back sides of the seed do not allow any dislocation generation during none of the examined experiments, excepted very scarce ones likely due to seed handling. Thus, from the current experimental observations and under the present experimental conditions, it seems that the industrial wafer double sided mechano - chemically surface polishing (SIL'TRONIX Silicon Technologies ${ }^{[27]}$ ), efficiently removes all dislocation sources and thus prevents the propagation of dislocations in the seed. 


\section{Conclusions}

Temperature ramp heating experiments have been carried out in a directional solidification furnace on diamond wire saw FZ - Si seed with different in plane crystallographic orientations. The in situ $\mathrm{X}$ - ray diffraction imaging investigations performed during the heating process reveal that the wafering process induces dislocation sources via deformation and/or micro-cleavage at the edges of the seed. Lattice distortion, limited only to the edges, appears on the diffraction images even at very low temperature (lower than $873 \mathrm{~K}$ ). When increasing the temperature, the edges become more strained and eventually dislocations nucleate, forming half-loops but always remaining close to the edges. When temperature reaches $1373 \mathrm{~K}$, dislocation propagation occurs throughout the entire width of the seed with, interestingly, the activation of specific crystallographic slip planes depending on the seed crystallographic orientation. This preferential activation of slip systems allows us to essentially attribute it to an applied external stress induced by the crucible holding system, lying along $\langle 110\rangle$, across the thickness of the seed. When the examined seeds are chemically polished after the cutting process, in order to remove the edge damage and thus the dislocation sources, the dislocation propagation event is delayed during the heating process; it happens at $1673 \mathrm{~K}$. In all cases, dislocation generation is not observed on the front and back side of the wafer denoting that the industrial wafer double sided mechano - chemical surface polishing efficiently removes all dislocation sources. Knowing that in the mono - like Si process dislocations formed in the seeds during the heating and melting process expand in the growing ingot afterwards during the solidification process, seed cutting and surface preparation is of major importance. Sources of dislocations need to be eliminated both at the surfaces of the seeds that are in contact with the anti-releasing coating of the crucible below, and the silicon feedstock above and their side edges as well, during the cutting and preparation process. A special care must be taken to limit 
mechanical stresses on the seeds, such as the ones induced by the weight of the feedstock on the top of the seed.

\section{Acknowledgments}

This work is funded by the ANR Project CrySaLID (N_ANR-14-CE05-0046-01). The ESRF (European Synchrotron Radiation Facility) BM05 team is greatly acknowledged for support during the X-ray imaging experiments.

\section{References}

[1] X. Gu, X. Yu, K. Guo, L. Chen, D. Wang, D. Yang, Seed-assisted cast quasi-single crystalline silicon for photovoltaic application: Towards high efficiency and low cost silicon solar cells, Sol. Energy Mater. Sol. Cells. 2012 101, 95-101. doi:10.1016/j.solmat.2012.02.024.

[2] F. Jay, D. Muñoz, T. Desrues, E. Pihan, V. Amaral de Oliveira, N. Enjalbert, A. Jouini, Advanced process for n-type mono-like silicon a-Si:H/c-Si heterojunction solar cells with 21.5\% efficiency, Sol. Energy Mater. Sol. Cells. 2014 130, 690-695. doi:10.1016/j.solmat.2014.02.025.

[3] M. Mrcarica, Potential for mono-cast material to achieve high efficiencies in mass production, Photovolt. Int. 2013 19, 28.

[4] M.G. Tsoutsouva, V.A. Oliveira, D. Camel, J. Baruchel, B. Marie, T.A. Lafford, Monolike silicon ingots grown on low angle misoriented seeds: Defect characterization by synchrotron X-ray diffraction imaging, Acta Mater. 2015 88, 112-120. doi:10.1016/j.actamat.2015.01.012. 
[5] M. Trempa, C. Reimann, J. Friedrich, G. Müller, A. Krause, L. Sylla, T. Richter, Influence of grain boundaries intentionally induced between seed plates on the defect generation in quasi-mono-crystalline silicon ingots, Cryst. Res. Technol. 2015 50, 124132. doi:10.1002/crat.201400226.

[6] M. Trempa, C. Reimann, J. Friedrich, G. Müller, A. Krause, L. Sylla, T. Richter, Defect formation induced by seed-joints during directional solidification of quasi-monocrystalline silicon ingots, J. Cryst. Growth. $\mathbf{2 0 1 4}$ 405, 131-141. doi:10.1016/j.jcrysgro.2014.08.002.

[7] K.E. Ekstrøm, G. Stokkan, R. Søndenå, H. Dalaker, T. Lehmann, L. Arnberg, M. Di Sabatino, Structure and dislocation development in mono-like silicon, Phys. Status Solidi A. 2015 212, 2278-2288. doi:10.1002/pssa.201532105.

[8] M.G. Tsoutsouva, V.A. Oliveira, D. Camel, T.N. Tran Thi, J. Baruchel, B. Marie, T.A. Lafford, Segregation, precipitation and dislocation generation between seeds in directionally solidified mono-like silicon for photovoltaic applications, J. Cryst. Growth. 2014 401, 397-403. doi:10.1016/j.jcrysgro.2013.12.022.

[9] A. Autruffe, M. Kivambe, L. Arnberg, M. Di Sabatino, The impact of oxygen precipitation on dislocation generation at small angle grain boundaries during seed-assisted directional solidification of silicon, Phys. Status Solidi A. 2016 213, 122-126. doi:10.1002/pssa.201532651.

[10] V. A. Oliveira, Influence of processing parameters on the generation and propagation of electrically active crystalline defects in monolike silicon, Phd Thesis, University Grenoble Alpes, France, 2016. 
[11] K. Jiptner, B. Gao, H. Harada, Y. Miyamura, M. Fukuzawa, K. Kakimoto, T. Sekiguchi, Thermal stress induced dislocation distribution in directional solidification of Si for PV application, J. Cryst. Growth. 2014 408, 19-24. doi:10.1016/j.jcrysgro.2014.09.017.

[12] T. Ervik, G. Stokkan, T. Buonassisi, Ø. Mjøs, O. Lohne, Dislocation formation in seeds for quasi-monocrystalline silicon for solar cells, Acta Mater. 2014 67, 199-206. doi:10.1016/j.actamat.2013.12.010.

[13] V.A. Oliveira, M. Tsoutsouva, T. Lafford, E. Pihan, F. Barou, D. Camel, Sub-grain boundaries sources and effects in large mono-like silicon ingots for PV, in $29^{\text {th }} E U$ PVSEC, Amsterdam, Netherlands, 2014: pp. 793-797. doi: 10.4229/EUPVSEC201420142AV.1.52

[14] K. Tempelhoff, F. Spiegelberg, R. Gleichmann, D. Wruck, Precipitation of oxygen in dislocation-free silicon, Phys. Status Solidi A. 1979 56, 213-223. doi:10.1002/pssa.2210560123.

[15] A. Tandjaoui, N. Mangelinck-Noël, G. Reinhart, J.-J. Furter, B. Billia, T. Lafford, J. Baruchel, X. Guichard, Real Time Observation of the Directional Solidification of Multicrystalline Silicon: X-ray Imaging Characterization, Energy Procedia 201227 (2012) 82-87. doi:10.1016/j.egypro.2012.07.033.

[16] A. Tandjaoui, N. Mangelinck-Noel, G. Reinhart, B. Billia, T. Lafford, J. Baruchel, Investigation of grain boundary grooves at the solid-liquid interface during directional solidification of multi-crystalline silicon: in situ characterization by X-ray imaging, $J$. Cryst. Growth. 2013, 377, 203-211. doi:10.1016/j.jcrysgro.2013.05.023. 
[17] T. Riberi-Béridot, N. Mangelinck-Noël, A. Tandjaoui, G. Reinhart, B. Billia, T. Lafford, J. Baruchel, L. Barrallier, On the impact of twinning on the formation of the grain structure of multi-crystalline silicon for photovoltaic applications during directional solidification, J. Cryst. Growth. 2015, 418, 38-44. doi:10.1016/j.jcrysgro.2015.02.024.

[18] A. Tandjaoui, N. Mangelinck-Noel, G. Reinhart, B. Billia, X. Guichard, Twinning occurrence and grain competition in multi-crystalline silicon during solidification, $C$. $R$. Phy. 2013, 14, 141-148. doi:10.1016/j.crhy.2012.12.001.

[19] M.G. Tsoutsouva, T. Riberi - Béridot, G. Regula, G. Reinhart, J. Baruchel, F. Guittonneau, L. Barrallier, N. Mangelinck-Noël, In situ investigation of the structural defect generation and evolution during the directional solidification of $\langle 110\rangle$ seeded growth Si, Acta Mater. 2016, 115, 210-223. doi:10.1016/j.actamat.2016.06.004.

[20] R. C. Burns, A. I. Chumakov, S. H. Connell, D. Dube, H. P. Godfried, J. O. Hansen, J. Härtwig, J. Hoszowska, F. Masiello, L. Mkhonza, M. Rebak, A. Rommevaux, R. Setshedi and P. Van Vaerenbergh, HPHT growth and x-ray characterization of high-quality type IIa diamond, J. Phys.: Condens. Matter. 2009, 21, 364224. doi:10.1088/0953$8984 / 21 / 36 / 364224$

[21] H. Wu, S.N. Melkote, S. Danyluk, Mechanical Strength of Silicon Wafers Cut by Loose Abrasive Slurry and Fixed Abrasive Diamond Wire Sawing, Adv. Eng. Mater. 2012, 14, 342-348. doi:10.1002/adem.201100263.

[22] V. Pogue, Measurement and analysis of wire sawing induced residual stress in photovoltaic silicon wafers, Master Thesis, Georgia Tech Theses and Dissertations, 2016. https://smartech.gatech.edu/handle/1853/55071. 
[23] B. Sopori, S. Devayajanam, P. Basnyat, 1 National Renewable Energy Laboratory, Golden, CO 80401, USA, Surface characteristics and damage distributions of diamond wire sawn wafers for silicon solar cells, AIMS Mater. Sci. 2016, 3 669-685. doi:10.3934/matersci.2016.2.669.

[24] W.B. E. Schmid, Plasticity of Crystals, with special Reference to Metals, Kristallplastizität: Mit Besonderer Berücksichtigung der Metalle, Springer, 1935. http://www.springer.com/la/book/9781504119276 (accessed April 4, 2017).

[25] J. Wittge, A. Danilewsky, D. Allen, P. McNally, Z.J. Li, T. Baumbach, E. GorosteguiColinas, J. Garagorri, M.R. Elizalde, D. Jacques, M.C. Fossati, D.K. Bowen, B.K. Tanner, X-ray diffraction imaging of dislocation generation related to microcracks in Si wafers, Powder Diffr. 2010, 25, 99-103. doi:10.1154/1.3392369.

[26] J. Wittge, A.N. Danilewsky, D. Allen, P. McNally, Z. Li, T. Baumbach, E. GorosteguiColinas, J. Garagorri, M.R. Elizalde, D. Jacques, M.C. Fossati, D.K. Bowen, B.K. Tanner, Dislocation sources and slip band nucleation from indents on silicon wafers, J. Appl. Crystallogr. 2010, 43, 1036-1039. doi:10.1107/S0021889810029894.

[27] http://www.sil-tronix-st.com/home/silicon-wafers/surface-preparation 


\section{Appendix}

Let us determine the matrix components in the crystallographic coordinates system (Ro) of a stress applied along the $\mathrm{y}$ axis in $\left(\mathrm{R}_{\mathrm{FZ}<100>}\right)$ (see table below) since this seed does exhibit morphology A dislocations when vertical temperature gradient $\mathrm{G}_{1}$ is still set to zero at $1073 \mathrm{~K}$. In this appendix, the activated glide systems are written in bold and the primary ones are in red. At high temperature, both primary and secondary glide systems are usually activated.

In all the studied seeds dislocations are visible solely in (111) and (11̄).

Table giving the method to determine the stress matrix for $\mathrm{FZ}_{<100\rangle}$ : a) scheme of both coordinate systems (crystallographic $(R o)$ or linked to the sample $\left.\left(R_{F Z<100>}\right)\right)$; b) to e) determination of the components of the stress matrix in (Ro) due to a stress applied along $y$ in $\left(R_{F Z<100>}\right)$. Note that ${ }^{t}\left(R_{z}\left(45^{\circ}\right)\right)$ is the transposed matrix of $\left(\operatorname{Rz}\left(45^{\circ}\right)\right)$ which is the rotation matrix of $45^{\circ}$ about the $z$ axis.

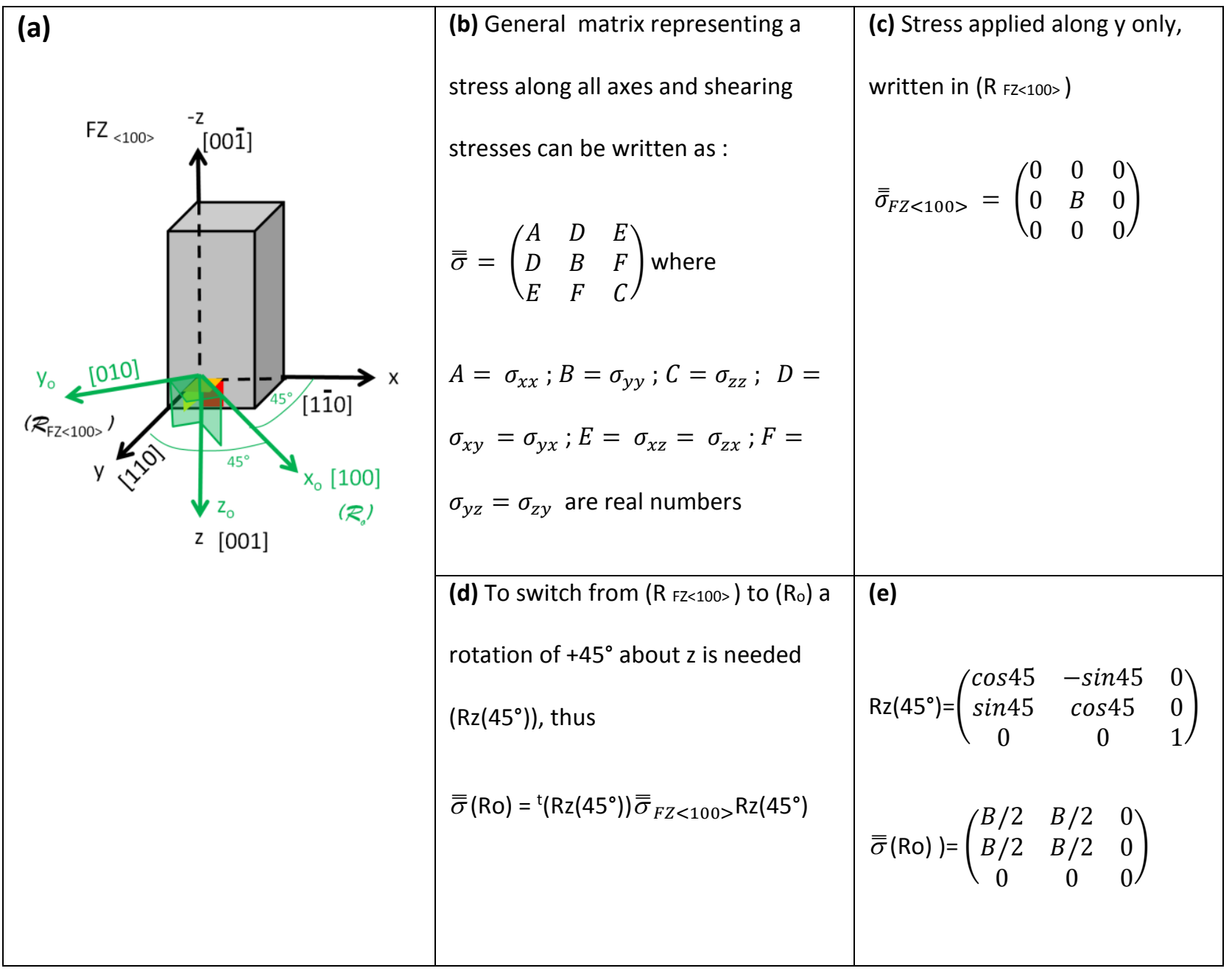


Let us check now that the resolved shear stresses which are $\overline{\bar{\sigma}}(\mathrm{Ro}) \cdot \overrightarrow{\mathrm{n}\{111\}} \cdot \overrightarrow{\mathrm{b}}$, where

$\mathrm{h}, \mathrm{k}, \mathrm{l}$ are the Miller indexes of the four glide systems and $\overrightarrow{\mathrm{b}}$ is each of the three Burger vectors belonging to each $\{111\}$, is in good agreement with the simple calculation of Schmid factor. Indeed we find with the letter "a" being the Si lattice parameter:

$\left(\begin{array}{ccc}B / 2 & B / 2 & 0 \\ B / 2 & B / 2 & 0 \\ 0 & 0 & 0\end{array}\right)\left(\begin{array}{l}\mathbf{1} \\ \mathbf{1} \\ \mathbf{1}\end{array}\right)=\left(\begin{array}{l}B \\ B \\ 0\end{array}\right) \neq \overrightarrow{0}$ and $\left(\begin{array}{l}B \\ B \\ 0\end{array}\right) \cdot a / 2\left(\begin{array}{c}\mathbf{0} \\ \mathbf{1} \\ \mathbf{- 1}\end{array}\right)=a B / 2 ;\left(\begin{array}{l}B \\ B \\ 0\end{array}\right) \cdot a / 2\left(\begin{array}{c}\mathbf{1} \\ \mathbf{0} \\ \mathbf{- 1}\end{array}\right)=a B / 2 ;\left(\begin{array}{c}B \\ B \\ 0\end{array}\right) \cdot\left(\begin{array}{c}-1 \\ 1 \\ 0\end{array}\right)=0$

$\left(\begin{array}{ccc}B / 2 & B / 2 & 0 \\ B / 2 & B / 2 & 0 \\ 0 & 0 & 0\end{array}\right)\left(\begin{array}{r}\mathbf{1} \\ \mathbf{1} \\ \mathbf{- 1}\end{array}\right)=\left(\begin{array}{l}B \\ B \\ 0\end{array}\right) \neq \overrightarrow{0}$ and $\left(\begin{array}{l}B \\ B \\ 0\end{array}\right) \cdot a / 2\left(\begin{array}{c}-1 \\ 1 \\ 0\end{array}\right)=0 ;\left(\begin{array}{l}B \\ B \\ 0\end{array}\right) \cdot a / 2\left(\begin{array}{l}\mathbf{1} \\ \mathbf{0} \\ \mathbf{1}\end{array}\right)=a B / 2 ;\left(\begin{array}{l}B \\ B \\ 0\end{array}\right) \cdot a / 2\left(\begin{array}{l}\mathbf{0} \\ \mathbf{1} \\ \mathbf{1}\end{array}\right)=a B / 2$

$\left(\begin{array}{ccc}B / 2 & B / 2 & 0 \\ B / 2 & B / 2 & 0 \\ 0 & 0 & 0\end{array}\right)\left(\begin{array}{c}-1 \\ 1 \\ 1\end{array}\right)=\left(\begin{array}{l}0 \\ 0 \\ 0\end{array}\right)=\overrightarrow{0}$ and $\left(\begin{array}{ccc}B / 2 & B / 2 & 0 \\ B / 2 & B / 2 & 0 \\ 0 & 0 & 0\end{array}\right)\left(\begin{array}{r}1 \\ -1 \\ 1\end{array}\right)=\left(\begin{array}{l}0 \\ 0 \\ 0\end{array}\right)=\overrightarrow{0}$

All is in agreement with simple Schmid factor calculations.

Now let us evaluate the resolved shear stress due to a pure shear in the (xy) plane (see table) for instance, due to a vertical temperature gradient $\mathrm{G}_{1}$ (which can be voluntarily applied or being residual even when the top and bottom temperature of the resistors are set equal, which should not happen since the furnace is designed to master their temperature);

$$
\begin{aligned}
& \overline{\bar{\sigma}}\left(\mathrm{R}_{\mathrm{FZ}<100>}\right)=\left(\begin{array}{lll}
0 & \mathrm{D} & 0 \\
\mathrm{D} & 0 & 0 \\
0 & 0 & 0
\end{array}\right) \text { and thus } \\
& \overline{\bar{\sigma}}(R o)={ }^{t}\left(R z\left(45^{\circ}\right)\right) \overline{\bar{\sigma}}\left(R_{F Z<100>}\right) R z\left(45^{\circ}\right) \\
& \overline{\bar{\sigma}}(R o)=\left(\begin{array}{ccc}
\frac{1}{\sqrt{2}} & \frac{1}{\sqrt{2}} & 0 \\
-\frac{1}{\sqrt{2}} & \frac{1}{\sqrt{2}} & 0 \\
0 & 0 & 1
\end{array}\right)\left(\begin{array}{lll}
0 & D & 0 \\
D & 0 & 0 \\
0 & 0 & 0
\end{array}\right)\left(\begin{array}{ccc}
\frac{1}{\sqrt{2}} & -\frac{1}{\sqrt{2}} & 0 \\
\frac{1}{\sqrt{2}} & \frac{1}{\sqrt{2}} & 0 \\
0 & 0 & 1
\end{array}\right)=\left(\begin{array}{ccc}
\frac{1}{\sqrt{2}} & \frac{1}{\sqrt{2}} & 0 \\
-\frac{1}{\sqrt{2}} & \frac{1}{\sqrt{2}} & 0 \\
0 & 0 & 1
\end{array}\right)\left(\begin{array}{ccc}
\frac{D}{\sqrt{2}} & \frac{D}{\sqrt{2}} & 0 \\
\frac{D}{\sqrt{2}} & -\frac{D}{\sqrt{2}} & 0 \\
0 & 0 & 0
\end{array}\right) \\
& \overline{\bar{\sigma}}(R o)=\left(\begin{array}{ccc}
D & 0 & 0 \\
0 & -D & 0 \\
0 & 0 & 0
\end{array}\right)
\end{aligned}
$$


Once more, let us calculate the resolved shear stress on the 12 different glide systems:

$\left(\begin{array}{ccc}D & 0 & 0 \\ 0 & -D & 0 \\ 0 & 0 & 0\end{array}\right)\left(\begin{array}{l}\mathbf{1} \\ \mathbf{1}\end{array}\right)=\left(\begin{array}{r}D \\ -D \\ 0\end{array}\right) \neq \overrightarrow{0}$ and $\left(\begin{array}{r}D \\ -D \\ 0\end{array}\right) \cdot a / 2\left(\begin{array}{r}\mathbf{0} \\ \mathbf{1} \\ -\mathbf{1}\end{array}\right)=-a D / 2 ;\left(\begin{array}{r}D \\ -D \\ 0\end{array}\right) \cdot a / 2\left(\begin{array}{r}\mathbf{1} \\ \mathbf{0} \\ -\mathbf{1}\end{array}\right)=a D / 2 ;$

$\left(\begin{array}{r}D \\ -D \\ 0\end{array}\right) \cdot a / 2\left(\begin{array}{r}-1 \\ 1 \\ 0\end{array}\right)=-a D$

$\left(\begin{array}{ccc}D & 0 & 0 \\ 0 & -D & 0 \\ 0 & 0 & 0\end{array}\right)\left(\begin{array}{r}\mathbf{1} \\ \mathbf{1} \\ -\mathbf{1}\end{array}\right)=\left(\begin{array}{r}D \\ -D \\ 0\end{array}\right) \neq \overrightarrow{0}$ and $\left(\begin{array}{r}D \\ -D \\ 0\end{array}\right) \cdot a / 2\left(\begin{array}{r}-\mathbf{1} \\ \mathbf{1} \\ \mathbf{0}\end{array}\right)=-a D ;\left(\begin{array}{r}D \\ -D \\ 0\end{array}\right) \cdot a / 2\left(\begin{array}{l}\mathbf{0} \\ \mathbf{1} \\ \mathbf{1}\end{array}\right)=-a D / 2 ;$

$\left(\begin{array}{r}D \\ -D \\ 0\end{array}\right) a / 2\left(\begin{array}{l}\mathbf{1} \\ \mathbf{0} \\ \mathbf{1}\end{array}\right)=a D / 2$

$\left(\begin{array}{ccc}D & 0 & 0 \\ 0 & -D & 0 \\ 0 & 0 & 0\end{array}\right)\left(\begin{array}{c}-\mathbf{1} \\ \mathbf{1} \\ \mathbf{1}\end{array}\right)=\left(\begin{array}{c}-D \\ -D \\ 0\end{array}\right) \neq \overrightarrow{0}$ and $\left(\begin{array}{r}-D \\ -D \\ 0\end{array}\right) \cdot a / 2\left(\begin{array}{r}\mathbf{0} \\ \mathbf{1} \\ -\mathbf{1}\end{array}\right)=-a D / 2 ;\left(\begin{array}{r}-D \\ -D \\ 0\end{array}\right) \cdot a / 2\left(\begin{array}{l}\mathbf{1} \\ \mathbf{1} \\ \mathbf{0}\end{array}\right)=-a D$

$\left(\begin{array}{c}-D \\ -D \\ 0\end{array}\right) \cdot a / 2\left(\begin{array}{c}\mathbf{1} \\ \mathbf{0} \\ \mathbf{1}\end{array}\right)=-a D / 2$

$\left(\begin{array}{ccc}D & 0 & 0 \\ 0 & -D & 0 \\ 0 & 0 & 0\end{array}\right)\left(\begin{array}{r}\mathbf{1} \\ \mathbf{1} \\ \mathbf{1}\end{array}\right)=\left(\begin{array}{c}D \\ D \\ 0\end{array}\right) \neq \overrightarrow{0}$ and $\left(\begin{array}{c}D \\ D \\ 0\end{array}\right) \cdot a / 2\left(\begin{array}{l}\mathbf{1} \\ \mathbf{1}\end{array}\right)=a D ;\left(\begin{array}{c}D \\ D \\ 0\end{array}\right) \cdot a / 2\left(\begin{array}{l}\mathbf{0} \\ \mathbf{1} \\ \mathbf{1}\end{array}\right)=a D / 2$

$\left(\begin{array}{c}D \\ D \\ 0\end{array}\right) \cdot a / 2\left(\begin{array}{r}\mathbf{1} \\ \mathbf{r} \\ -\mathbf{1}\end{array}\right)=a D / 2$

In conclusion, with a shear stress in xy sample plane, all glide systems can be possibly excited and in particular the ones having a common Burgers vector in each couple of either experimentally active glide planes (see figure $3 \mathrm{~b}$ of the submitted paper) such as (111) and (11) $)$ with $\overrightarrow{\mathrm{b}}=a / 2[\overline{1} 10]$ and the non-experimentally active glide planes such as $(\overline{1} 1 \overline{1})$ and (111) with $\overrightarrow{\mathrm{b}}=a / 2[110]$ : all these four primary glide systems have the same probability to relieve stress.

Now let us evaluate the resolved shear stress due to a pure shear in the (xz) plane (see table) for instance, due to a horizontal temperature gradient $G_{t}$. In the sample coordinates, the corresponding stress matrix would be written as: 


$$
\begin{aligned}
& \overline{\bar{\sigma}}\left(R_{F Z<100>}\right)=\left(\begin{array}{lll}
0 & 0 & E \\
0 & 0 & 0 \\
E & 0 & 0
\end{array}\right) \text { and can be written in }(R o) \text { as } \\
& \overline{\bar{\sigma}}(R o)=\left(\begin{array}{ccc}
\frac{1}{\sqrt{2}} & \frac{1}{\sqrt{2}} & 0 \\
-\frac{1}{\sqrt{2}} & \frac{1}{\sqrt{2}} & 0 \\
0 & 0 & 1
\end{array}\right)\left(\begin{array}{ccc}
0 & 0 & E \\
0 & 0 & 0 \\
E & 0 & 0
\end{array}\right)\left(\begin{array}{ccc}
\frac{1}{\sqrt{2}} & -\frac{1}{\sqrt{2}} & 0 \\
\frac{1}{\sqrt{2}} & \frac{1}{\sqrt{2}} & 0 \\
0 & 0 & 1
\end{array}\right) \\
& \overline{\bar{\sigma}}(R o)=\left(\begin{array}{ccc}
\frac{1}{\sqrt{2}} & \frac{1}{\sqrt{2}} & 0 \\
-\frac{1}{\sqrt{2}} & \frac{1}{\sqrt{2}} & 0 \\
0 & 0 & 1
\end{array}\right)\left(\begin{array}{ccc}
0 & 0 & E \\
0 & 0 & 0 \\
\frac{E}{\sqrt{2}} & -\frac{E}{\sqrt{2}} & 0
\end{array}\right)=\left(\begin{array}{ccc}
0 & 0 & \frac{E}{\sqrt{2}} \\
0 & 0 & -\frac{E}{\sqrt{2}} \\
\frac{E}{\sqrt{2}} & -\frac{E}{\sqrt{2}} & 0
\end{array}\right)
\end{aligned}
$$

Once more, let us calculate the resolved shear stress on the 12 different glide systems:

$$
\left(\begin{array}{ccc}
0 & 0 & \frac{E}{\sqrt{2}} \\
0 & 0 & -\frac{E}{\sqrt{2}} \\
\frac{E}{\sqrt{2}} & -\frac{E}{\sqrt{2}} & 0
\end{array}\right)\left(\begin{array}{l}
\mathbf{1} \\
\mathbf{1} \\
\mathbf{1}
\end{array}\right)=\left(\begin{array}{c}
\frac{E}{\sqrt{2}} \\
-\frac{E}{\sqrt{2}} \\
0
\end{array}\right) \neq \overrightarrow{0} ;\left(\begin{array}{c}
\frac{E}{\sqrt{2}} \\
-\frac{E}{\sqrt{2}} \\
0
\end{array}\right) \cdot a / 2\left(\begin{array}{c}
\mathbf{0} \\
\mathbf{1} \\
-\mathbf{1}
\end{array}\right)=-a E /(2 \sqrt{2}) ;\left(\begin{array}{c}
\frac{E}{\sqrt{2}} \\
-\frac{E}{\sqrt{2}} \\
0
\end{array}\right) \cdot a / 2\left(\begin{array}{c}
\mathbf{1} \\
\mathbf{0} \\
-\mathbf{1}
\end{array}\right)=a E /(2 \sqrt{2}) ;
$$$$
\left(\begin{array}{c}
\frac{E}{\sqrt{2}} \\
-\frac{E}{\sqrt{2}} \\
0
\end{array}\right) a / 2\left(\begin{array}{r}
-1 \\
1 \\
0
\end{array}\right)=-a E / \sqrt{2}
$$$$
\left(\begin{array}{ccc}
0 & 0 & \frac{E}{\sqrt{2}} \\
0 & 0 & -\frac{E}{\sqrt{2}} \\
\frac{E}{\sqrt{2}} & -\frac{E}{\sqrt{2}} & 0
\end{array}\right)\left(\begin{array}{c}
\mathbf{1} \\
\mathbf{1} \\
-\mathbf{1}
\end{array}\right)=\left(\begin{array}{c}
-\frac{E}{\sqrt{2}} \\
+\frac{E}{\sqrt{2}} \\
0
\end{array}\right) \neq \overrightarrow{0} ;\left(\begin{array}{c}
-\frac{E}{\sqrt{2}} \\
+\frac{E}{\sqrt{2}} \\
0
\end{array}\right) \cdot a / 2\left(\begin{array}{c}
-\mathbf{1} \\
\mathbf{1} \\
\mathbf{0}
\end{array}\right)=a E / \sqrt{2} ;\left(\begin{array}{c}
-\frac{E}{\sqrt{2}} \\
+\frac{E}{\sqrt{2}} \\
0
\end{array}\right) a / 2\left(\begin{array}{l}
\mathbf{0} \\
\mathbf{1} \\
\mathbf{1}
\end{array}\right)=a E /(2 \sqrt{2}) ;
$$$$
\left(\begin{array}{c}
-\frac{e}{\sqrt{2}} \\
+\frac{e}{\sqrt{2}} \\
0
\end{array}\right) a / 2\left(\begin{array}{l}
\mathbf{1} \\
\mathbf{0} \\
\mathbf{1}
\end{array}\right)=a E /(2 \sqrt{2})
$$$$
\left(\begin{array}{ccc}
0 & 0 & \frac{E}{\sqrt{2}} \\
0 & 0 & -\frac{E}{\sqrt{2}} \\
\frac{E}{\sqrt{2}} & -\frac{E}{\sqrt{2}} & 0
\end{array}\right)\left(\begin{array}{c}
-\mathbf{1} \\
\mathbf{1} \\
\mathbf{1}
\end{array}\right)=\left(\begin{array}{c}
\frac{E}{\sqrt{2}} \\
-\frac{E}{\sqrt{2}} \\
-\sqrt{2} E
\end{array}\right) \neq \overrightarrow{0} ;\left(\begin{array}{c}
\frac{E}{\sqrt{2}} \\
-\frac{E}{\sqrt{2}} \\
-\sqrt{2} E
\end{array}\right) a / 2\left(\begin{array}{c}
\mathbf{0} \\
\mathbf{1} \\
-\mathbf{1}
\end{array}\right)=a E /(2 \sqrt{2})\left(\begin{array}{c}
\frac{E}{\sqrt{2}} \\
-\frac{E}{\sqrt{2}} \\
-\sqrt{2} E
\end{array}\right) a / 2\left(\begin{array}{l}
1 \\
1 \\
0
\end{array}\right)=0
$$$$
\left(\begin{array}{c}
\frac{E}{\sqrt{2}} \\
-\frac{E}{\sqrt{2}} \\
-\sqrt{2} E
\end{array}\right) a / 2\left(\begin{array}{l}
\mathbf{1} \\
\mathbf{0} \\
\mathbf{1}
\end{array}\right)=-a E /(2 \sqrt{2})
$$ 


$$
\begin{aligned}
& \left(\begin{array}{ccc}
0 & 0 & \frac{E}{\sqrt{2}} \\
0 & 0 & -\frac{E}{\sqrt{2}} \\
\frac{E}{\sqrt{2}} & -\frac{E}{\sqrt{2}} & 0
\end{array}\right)\left(\begin{array}{r}
\mathbf{1} \\
-\mathbf{1} \\
\mathbf{1}
\end{array}\right)=\left(\begin{array}{c}
\frac{E}{\sqrt{2}} \\
-\frac{E}{\sqrt{2}} \\
\sqrt{2} E
\end{array}\right) \neq \overrightarrow{0} ;\left(\begin{array}{c}
\frac{E}{\sqrt{2}} \\
-\frac{E}{\sqrt{2}} \\
\sqrt{2} E
\end{array}\right) \cdot a / 2\left(\begin{array}{c}
1 \\
1 \\
0
\end{array}\right)=0 ;\left(\begin{array}{c}
\frac{E}{\sqrt{2}} \\
-\frac{E}{\sqrt{2}} \\
\sqrt{2} E
\end{array}\right) a / 2\left(\begin{array}{c}
\mathbf{0} \\
\mathbf{1} \\
\mathbf{1}
\end{array}\right)=a E /(2 \sqrt{2}) ; \\
& \left(\begin{array}{c}
\frac{E}{\sqrt{2}} \\
-\frac{E}{\sqrt{2}} \\
\sqrt{2} E
\end{array}\right) a / 2\left(\begin{array}{c}
\mathbf{1} \\
\mathbf{0} \\
-\mathbf{1}
\end{array}\right)=-a E /(2 \sqrt{2})
\end{aligned}
$$

If any shear stress existed in xz plane, unless only the primary planes were excited the $(\overline{1} 11)$ and $(\overline{1} 1 \overline{1})$ should also have been excited (unless the resolved shear stress in those planes is still too low to move dislocations).

Eventually, let us see the effect of the presence of a shear stress in the (yz) plane of the sample (temperature gradient existing indeed across the width of the seed $G_{w}$ ):

$$
\begin{aligned}
& \overline{\bar{\sigma}}\left(R_{F Z<100>}\right)=\left(\begin{array}{lll}
0 & 0 & 0 \\
0 & 0 & F \\
0 & F & 0
\end{array}\right) \text { and can be written in }(R o) \text { as } \\
& \overline{\bar{\sigma}}(R o)=\left(\begin{array}{ccc}
\frac{1}{\sqrt{2}} & \frac{1}{\sqrt{2}} & 0 \\
-\frac{1}{\sqrt{2}} & \frac{1}{\sqrt{2}} & 0 \\
0 & 0 & 1
\end{array}\right)\left(\begin{array}{lll}
0 & 0 & 0 \\
0 & 0 & F \\
0 & F & 0
\end{array}\right)\left(\begin{array}{ccc}
\frac{1}{\sqrt{2}} & -\frac{1}{\sqrt{2}} & 0 \\
\frac{1}{\sqrt{2}} & \frac{1}{\sqrt{2}} & 0 \\
0 & 0 & 1
\end{array}\right) \\
& \overline{\bar{\sigma}}(R o)=\left(\begin{array}{ccc}
\frac{1}{\sqrt{2}} & \frac{1}{\sqrt{2}} & 0 \\
-\frac{1}{\sqrt{2}} & \frac{1}{\sqrt{2}} & 0 \\
0 & 0 & 1
\end{array}\right)\left(\begin{array}{ccc}
0 & 0 & 0 \\
0 & 0 & f \\
\frac{F}{\sqrt{2}} & \frac{F}{\sqrt{2}} & 0
\end{array}\right)=\left(\begin{array}{ccc}
0 & 0 & \frac{F}{\sqrt{2}} \\
0 & 0 & \frac{F}{\sqrt{2}} \\
\frac{F}{\sqrt{2}} & \frac{F}{\sqrt{2}} & 0
\end{array}\right)
\end{aligned}
$$

$$
\begin{aligned}
& \left(\begin{array}{ccc}
0 & 0 & \frac{F}{\sqrt{2}} \\
0 & 0 & \frac{F}{\sqrt{2}} \\
\frac{F}{\sqrt{2}} & \frac{F}{\sqrt{2}} & 0
\end{array}\right)\left(\begin{array}{c}
\mathbf{1} \\
\mathbf{1} \\
\mathbf{1}
\end{array}\right)=\left(\begin{array}{c}
\frac{F}{\sqrt{2}} \\
\frac{F}{\sqrt{2}} \\
\sqrt{2} F
\end{array}\right) \neq \overrightarrow{0} ;\left(\begin{array}{c}
\frac{F}{\sqrt{2}} \\
\frac{F}{\sqrt{2}} \\
\sqrt{2} F
\end{array}\right) a / 2\left(\begin{array}{c}
\mathbf{0} \\
\mathbf{1} \\
-\mathbf{1}
\end{array}\right)=-F a /(2 \sqrt{2}) ;\left(\begin{array}{c}
\frac{F}{\sqrt{2}} \\
\frac{F}{\sqrt{2}} \\
\sqrt{2} F
\end{array}\right) a / 2\left(\begin{array}{c}
\mathbf{1} \\
\mathbf{0} \\
-\mathbf{1}
\end{array}\right)=-F a /(2 \sqrt{2}) ; \\
& \left(\begin{array}{c}
\frac{F}{\sqrt{2}} \\
\frac{F}{\sqrt{2}} \\
\sqrt{2} F
\end{array}\right) a / 2\left(\begin{array}{c}
1 \\
1 \\
0
\end{array}\right)=0
\end{aligned}
$$




$$
\begin{aligned}
& \left(\begin{array}{ccc}
0 & 0 & \frac{F}{\sqrt{2}} \\
0 & 0 & \frac{F}{\sqrt{2}} \\
\frac{F}{\sqrt{2}} & \frac{F}{\sqrt{2}} & 0
\end{array}\right)\left(\begin{array}{r}
\mathbf{1} \\
\mathbf{1} \\
-\mathbf{1}
\end{array}\right)=\left(\begin{array}{c}
-\frac{F}{\sqrt{2}} \\
-\frac{F}{\sqrt{2}} \\
\sqrt{2} F
\end{array}\right) \neq \overrightarrow{0} ;\left(\begin{array}{c}
-\frac{F}{\sqrt{2}} \\
-\frac{F}{\sqrt{2}} \\
\sqrt{2} F
\end{array}\right) a / 2\left(\begin{array}{l}
\mathbf{1} \\
\mathbf{0} \\
\mathbf{1}
\end{array}\right)=F a /(2 \sqrt{2}) ; \quad\left(\begin{array}{c}
-\frac{F}{\sqrt{2}} \\
-\frac{F}{\sqrt{2}} \\
\sqrt{2} F
\end{array}\right) a / 2\left(\begin{array}{l}
\mathbf{0} \\
\mathbf{1} \\
\mathbf{1}
\end{array}\right)=F a /(2 \sqrt{2}) ; \\
& \left(\begin{array}{l}
-\frac{F}{\sqrt{2}} \\
-\frac{F}{\sqrt{2}} \\
\sqrt{2} F
\end{array}\right) \quad a / 2\left(\begin{array}{r}
-1 \\
1 \\
0
\end{array}\right)=0 \\
& \left(\begin{array}{ccc}
0 & 0 & \frac{F}{\sqrt{2}} \\
0 & 0 & \frac{F}{\sqrt{2}} \\
\frac{F}{\sqrt{2}} & \frac{F}{\sqrt{2}} & 0
\end{array}\right)\left(\begin{array}{c}
-\mathbf{1} \\
\mathbf{1} \\
\mathbf{1}
\end{array}\right)=\left(\begin{array}{c}
\frac{F}{\sqrt{2}} \\
\frac{F}{\sqrt{2}} \\
0
\end{array}\right) \neq \overrightarrow{0} ; \quad\left(\begin{array}{c}
\frac{F}{\sqrt{2}} \\
\frac{F}{\sqrt{2}} \\
0
\end{array}\right) a / 2\left(\begin{array}{c}
\mathbf{0} \\
\mathbf{1} \\
\mathbf{- 1}
\end{array}\right)=F a /(2 \sqrt{2}) ;\left(\begin{array}{c}
\frac{F}{\sqrt{2}} \\
\frac{F}{\sqrt{2}} \\
0
\end{array}\right) a / 2\left(\begin{array}{l}
\mathbf{1} \\
\mathbf{1} \\
\mathbf{0}
\end{array}\right)=F a / \sqrt{2} \quad ; \quad\left(\begin{array}{c}
\frac{F}{\sqrt{2}} \\
\frac{F}{\sqrt{2}} \\
0
\end{array}\right) \\
& a / 2\left(\begin{array}{l}
\mathbf{1} \\
\mathbf{0} \\
\mathbf{1}
\end{array}\right)=F a /(2 \sqrt{2}) \\
& \left(\begin{array}{ccc}
0 & 0 & \frac{F}{\sqrt{2}} \\
0 & 0 & \frac{F}{\sqrt{2}} \\
\frac{F}{\sqrt{2}} & \frac{F}{\sqrt{2}} & 0
\end{array}\right)\left(\begin{array}{r}
\mathbf{1} \\
\mathbf{1} \\
\mathbf{1}
\end{array}\right)=\left(\begin{array}{c}
\frac{F}{\sqrt{2}} \\
\frac{F}{\sqrt{2}} \\
0
\end{array}\right) \neq 0 ;\left(\begin{array}{c}
\frac{F}{\sqrt{2}} \\
\frac{F}{\sqrt{2}} \\
0
\end{array}\right) a / 2\left(\begin{array}{l}
\mathbf{1} \\
\mathbf{1} \\
\mathbf{0}
\end{array}\right)=F a / \sqrt{2} ;\left(\begin{array}{c}
\frac{F}{\sqrt{2}} \\
\frac{F}{\sqrt{2}} \\
0
\end{array}\right) a / 2\left(\begin{array}{r}
\mathbf{1} \\
\mathbf{0} \\
\mathbf{- 1}
\end{array}\right)=F a /(2 \sqrt{2}) \quad ;\left(\begin{array}{c}
\frac{F}{\sqrt{2}} \\
\frac{F}{\sqrt{2}} \\
0
\end{array}\right) \\
& a / 2\left(\begin{array}{l}
\mathbf{0} \\
\mathbf{1} \\
\mathbf{1}
\end{array}\right)=F a /(2 \sqrt{2})
\end{aligned}
$$

The primary glide planes would be in $(\overline{1} 11)$ and $(\overline{1} 1 \overline{1})$ planes having a Burgers vector $\overrightarrow{\mathrm{b}}=a / 2[110]$ which is not visible in figure $3 \mathrm{~b}$ of the paper, due to the used diffraction vector. Nevertheless, all other secondary glide systems would have then the same probability to relieve stress, thus both $(\overline{1} 11)$ and $(\overline{1} 1 \overline{1})$ would have contained visible dislocations.

It is likely that the main stress capable to drive dislocation through the entire crystal is a compression stress along the y axis of the seed. 